\title{
BIODEGRADATION OF PHENOL BY STENOTROPHOMONAS SP. AND STAPHYLOCOCCUS SP. ISOLATED FROM CONTAMINATED SITES
}

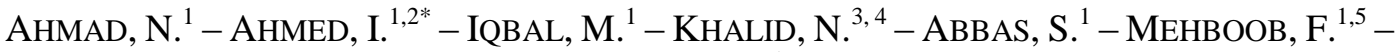 \\ AHAD, K. ${ }^{5}$ \\ ${ }^{I}$ PARC Institute of Advanced Studies in Agriculture, National Agricultural Research Centre \\ (NARC), Park Road, Islamabad-45500, Pakistan \\ ${ }^{2}$ Institute of Microbial Culture Collection of Pakistan (IMCCP), National Agricultural Research \\ Centre (NARC), Park Road, Islamabad-45500, Pakistan \\ ${ }^{3}$ School of Food and Agricultural Sciences, University of Management and Technology, Lahore \\ 54000, Pakistan \\ ${ }^{4}$ Centre for Chemistry and Biotechnology, School of Life and Environmental Sciences, Deakin \\ University, Waurn Ponds, Victoria 3216, Australia \\ ${ }^{5}$ Ecotoxicology Research Institute (ERI), National Agricultural Research Centre (NARC), Park \\ Road, Islamabad-45500, Pakistan \\ *Corresponding author \\ e-mail: iftikharnarc@hotmail.com \\ (phone: +92-51-9073 3729; fax: +92-51-9255034) \\ (Received 27 $7^{\text {th }}$ Apr 2016; accepted 22 ${ }^{\text {nd }}$ Jul 2016)
}

\begin{abstract}
Phenol as environmental pollutant is detrimental to living organisms and needed to be eliminated for environmental safety. Among the various practiced approaches for its removal, bacterial utilization gets attraction due to its eco-friendly and cost effective nature. For this purpose, bacterial strains were isolated from bioremediation site and industrial waste through enrichment in phenol $(250 \mathrm{mg}$ $\mathrm{L}^{-1}$ ) for 3 days at $28^{\circ} \mathrm{C}$. After enrichment, morphologically distinct colonies were purified on phenol (200 $\mathrm{mg} \mathrm{L}^{-1}$ ) agar plates and the strains were identified through $16 \mathrm{~S}$ rRNA gene sequence. Total of eight strains were identified, among them two strains, NCCP-310 and NCCP-405 had the best potential of phenol degradation which were identified as the members of the genera Stenotrophomonas and Staphylococcus. NCCP-310 and NCCP- 405 showed 98.85 and $98.9 \%$ sequence identity with Stenotrophomonas maltophilia and Staphylococcus equorum subsp. equorum, respectively. Both strains have ability to tolerate $1000 \mathrm{mg} \mathrm{L}^{-1}$ phenol. The isolated strains degraded $750 \mathrm{mg} \mathrm{L}^{-1}$ of phenol at $\mathrm{pH} 7$ and $28+2^{\circ} \mathrm{C}$. NCCP-310 and NCCP-405 showed degradation of such amount in 65 and $85 \mathrm{~h}$ with the average rate of 15.65 and $11.64 \mathrm{mg} \mathrm{L}^{-1} \mathrm{~h}^{-1}$. Our work suggests that these strains are efficient in phenol removal and could be used for bioremediation.
\end{abstract}

Keywords: phenol, biodegradation, Stenotrophomonas, Staphylococcus, bioremediation

\section{Introduction}

The foremost challenge of environmental concern is the elimination of pollutant that is liberated at alarming rate in our ecosystem and food chain due to rapid industrialization. Untreated industrial wastes containing xenobiotics drained up and contaminate water resources which are used for domestic as well as in agricultural practices (Kwon and Yeom, 2009; Ahmed et al., 2012). Phenol is used most widely in many industries such as pharmaceutical, plastic, ceramics, oil refinery, resin manufacturing, coke plant, textile and steel industries etc. (Han et al., 2010; Zhu et al., 2012) and due to its toxicity, phenol is in the priority list of US Environmental Protection Agency (US EPA, 2007). 
Phenol ranging from 10 to $17500 \mathrm{mg} \mathrm{L}^{-1}$ is detected in industrial effluent (Carbajo et al., 2010) while, only $0.5 \mathrm{mg} \mathrm{L}^{-1}$ is permitted by the Environmental Protection Agencies in the effluent based on production, exposure and biological effects (Giti et al., 2005). The contamination of water by phenol generates polychlorinated phenols which at low concentration $\left(2.0 \mu \mathrm{g} \mathrm{L}^{-1}\right)$ cause unpleasant smell in drinking water (Arutchelvan et al., 2006). Phenol is lethal for all form of life includes humans, animals, plants, aquatic life and microorganisms (Rocha et al., 2007). Proper hygienic techniques are obligatory to dispose bulk phenol containing effluents. To cope with this situation, many physical and chemical methods (adsorption, solvent extraction, activated carbon adsorption, chemical oxidation) are practiced which are no more desirable owing to high cost of production, hazardous to workers and nearby population (Idris and Saed, 2002). Therefore, biodegradation is the plausible approach for phenol removal because of low cost and eco-friendly nature (Saravanan et al., 2008).

Diverse groups of microorganisms including fungi, algae and bacteria are naturally endowed with the property of phenol degradation (Godjevargova et al., 2003; Fialova et al., 2004; Quan et al., 2004) and many bacterial isolates with high phenol degrading potential are evaluated belonging to various genera including Rhodococcus (Larkin et al., 2005), Stenotrophomonas (Urszula et al., 2009), Pseudomonas (Ahmad et al., 2014), etc.

The objectives of the current study were the isolation, identification of phenol degrading bacteria based on 16S rRNA gene and to determine their phenol degrading potential. We reported phenol degrading potential of Stenotrophomonas sp. NCCP-310 and Staphylococcus sp. NCCP-405 which was isolated from sludge of bioremediation site and industrial waste respectively.

\section{Materials and methods}

\section{Isolation and enrichment}

Samples (waste) were collected from two sites i.e. Bioremediation Garden, NARC and industrial area I-9 Islamabad, Pakistan. The enrichment of samples was conducted at ambient temperature for 3 days at $120 \mathrm{rpm}$ in mineral salt medium (MSM) containing phenol $\left(250 \mathrm{mg} \mathrm{L}^{-1}\right)$. Two to three drops of the enriched samples were spread on MSM plates containing only phenol $\left(200 \mathrm{mg} \mathrm{L}^{-1}\right)$ for carbon need. Plates were placed in incubator at $28{ }^{\circ} \mathrm{C}$ till growth. Morphologically distinct colonies appeared was subcultured and purified on phenol $\left(200 \mathrm{mg} \mathrm{L}^{-1}\right)$ containing agar plates again. Subculturing was perfumed many times to get pure culture. The isolated strains were preserved at $80^{\circ} \mathrm{C}$ in $70 \%$ glycerol solution.

\section{Identification of bacterial strains}

Identification of the isolated strains was performed on the bases of 16S rRNA gene followed by the method of Ahmed et al. (2007). For this purpose, pure culture of each strain was obtained by growing on Tryptic Soy Agar (TSA) plates incubated at $28^{\circ} \mathrm{C}$. After purification, single colony of each strain was dipped and stirred in TE buffer (20 $\mu \mathrm{L}$ ) in PCR strips, homogenized and kept in thermal cycler at $95^{\circ} \mathrm{C}$ for $10 \mathrm{~min}$ for extraction of DNA. Strips were then removed and centrifuged at $12000 \mathrm{rpm}$ for $5 \mathrm{~min}$. Genes of $16 \mathrm{~S}$ rRNA was amplified using $1 \mu \mathrm{L}$ template bacterial DNA contained in supernatant. $49 \mu \mathrm{L}$ master mix was prepared for each strain by mixing TAKARA pre- 
mix $(25 \mu \mathrm{L}), 2 \mu \mathrm{L}$ of each following primers: 9F (5'-GAGTTTGATCCTGGCTCAG$3^{\prime}$ ) and 1510R (5'-GGCTACCTTGTTACGA-3') and $20 \mu \mathrm{L}$ PCR water. The final reaction volume was made to $50 \mu \mathrm{L}$ in PCR tube by adding the prepared $49 \mu \mathrm{L}$ of master mix to $1 \mu \mathrm{L}$ of the template DNA which was already added to each PCR tube. In centrifuge machine the samples were short spin for a min or two for homogenization. PCR strips were then placed in thermal cycler (Applied Biosystems, Veriti, USA), PCR program was set as described by Ahmed et al. (2007) to amplify the said gene. Amplified products were confirmed by gel electrophoresis using $0.8 \%$ agarose in which, bromo phenol blue and ethidium bromide were used as loading dye and staining dye, respectively. Images of the gel were taken on gel documentation system (UVIPro Platinum, England). Purification of the Amplified products were done following the manufacturer's protocol (Invitrogen, USA). The amplified 16S rRNA gene products were sequenced using universal forward 27F (5'-AGAGTTTGATCMTGGCTCAG-3') and reverse 1492R (5'-ACCTTGTTACGACTT-3') primers.

The obtained sequences were refined with BioEdit software and to retrieve closest matches, BLAST search was performed on Ez-Taxon Server. On the basis of maximum identity score sequences were selected which were aligned in Clustal W (V. 1.6) (Thompson et al., 1994). Phylogenetic trees were generated in MEGA-6 software using Neighbor-Joining algorithms (Tamura et al., 2011).

\section{Biochemical characterization}

Consumption of different carbon sources by the isolates were determined using API $20 \mathrm{E}$ kit (bioMerieux, France). Few pure colonies (16 to $18 \mathrm{~h}$ ) of each strain were added in $0.85 \%$ saline solution and the microtubes of API 20E kit were filled with prepared inoculums. The kits were then placed in incubator at $28^{\circ} \mathrm{C}$ for $24-48 \mathrm{~h}$ and after then, the results were recorded according to color change.

\section{Phenol tolerance}

Phenol resistance of isolated strains was determined by introducing the pre-culture of each strain in MS broth augmented with 0, 250, 500, 750 and $1000 \mathrm{mg} \mathrm{L}^{-1}$ phenol in $100 \mathrm{~mL}$ flasks. Flask were placed on shaker within incubator at $28^{\circ} \mathrm{C}$ and incubated for 3-4 days. Blank without inoculum of each concentration was prepared in parallel. At different time gap growth was checked with the help of spectrophotometer (IMPLEN, Germany) at $600 \mathrm{~nm}$ wavelength. The growth of each strain at a given phenol concentration was determined with corresponding blank.

\section{Phenol degrading potential and analysis}

Phenol degrading efficiency of isolated strains was determined by adding the preculture of each strain in MSM broth augmented with $750 \mathrm{mg} \mathrm{L}^{-1}$ of phenol for 2-4 days at $200 \mathrm{rpm}$. Samples of the culture were collected at specific intervals for 3-5 days depending upon the growth of strain. Optical density (OD) of the samples was determined at $600 \mathrm{~nm}$ with spectrophotometer (IMPLEN, Germany) to observe the growth of cells over time.

One $\mathrm{mL}$ sample was taken from each flask at different time intervals and centrifuged at $12000 \mathrm{rpm}$ for 7-10 min. Then $0.5 \mathrm{~mL}$ of centrifuged sample was diluted with an equal amount of acetonitrile. High Performance Liquid Chromatography (HPLC) (PerkinElmer, USA) consisting of C-18 column together with LC 295 UV/V detector. 
Mobile phase was comprised of acetonitrile and water at the rate of $60: 40 \%(\mathrm{v} / \mathrm{v})$ with flow rate of $0.8 \mathrm{~mL} / \mathrm{min}$. Detector wavelength was set to $280 \mathrm{~nm}$ (Ahmad et al., 2014). Identification of phenol was done on the basis of retention time and quantification on the basis of 6 points external standards calibration curve. The data obtained from bacterial growth versus time and phenol degradation versus time was analyze using regression analysis.

\section{Results and discussion}

\section{Isolation and identification}

Eight bacterial isolates were isolated through enrichment in $250 \mathrm{mg} \mathrm{L}^{-1}$ phenol but, here we focus on two strains i.e. NCCP-310 and NCCP-405 which showed high phenol degrading potential. Enrichment of culture was often practiced to isolate the desired microorganisms among the diverse microbial populations (Dunbar et al., 1997). After purification, the strains were characterized morphologically. Colony of the NCCP-310 was pale yellow in color with round shape and entire margin. The elevation was convex. Shape of NCCP-405 was circular with white color having smooth surface. Margin of the colony was entire with flat elevation.

Isolated strains were identified using 16S rRNA gene to avoid problems raised in identification merely on morphological bases (Roohi et al., 2012). Refined sequences (16S rRNA gene) of NCCP-310 and NCCP-405 were deposited to DNA Data Bank of Japan (DDBJ) with the accession numbers AB983341 and AB983342, respectively. 16S rRNA gene sequence comparison of NCCP-310 showed that this strain shared $98.85 \%$ similarity with Stenotrophomonas maltophilia (AB008509) which was isolated by Hugh (1981) and assigned as Pseudomonas maltophilia but later on due to biochemical characterizations and 16S rRNA gene sequence affiliation, the strain was assigned as Stenotrophomonas maltophilia (Palleroni and Bradbury, 1993). This strain shared 98.85, 98.75 and 98.66\% sequence identity with Pseudomonas geniculata (AB021404), Pseudomonas hibiscicola (AB021405) and Pseudomonas beteli (AB021406), respectively. Phylogenetic analysis confirmed the affiliation of NCCP-310 (Fig. 1) with the above said strains but Anzai et al. (2000) performed phylogenetic analysis of $\gamma-\beta$ subclasses of the Proteobacteria and reclassified the strains as the members of the genus Stenotrophomonas. However, we suggest the DNA-DNA hybridization of NCCP310 with the closely related strains to determine the exact taxonomic position. NCCP405 exhibit 98.9, 98.8 and 97.79\% identity with Staphylococcus equorum subsp. Equorum (AB009939), Staphylococcus equorum subsp. Linens (AF527483) and Staphylococcus xylosus (D83374), respectively. Phylogenetic analysis (Fig. 2) affirmed the association of NCCP-405 with the genus Staphylococcus.

\section{Biochemical characterizations}

Using API 20E kit, the isolated strains were tested for various organic substrates utilization. Table 1 shows biochemical characterizations of Stenotrophomonas sp. NCCP-310 and Staphylococcus sp. NCCP-405. Both strains showed positive results for $\beta$-galactosidase and $\mathrm{NO}_{2}$ production. In addition, Stenotrophomonas sp. NCCP-310 showed positive results for lysine decarboxylase, citrate utilization, gelatinase while negative for all the other substrates used. Similarly, Staphylococcus sp. NCCP-405 showed positive results for urease while negative for all other substrates tested. 


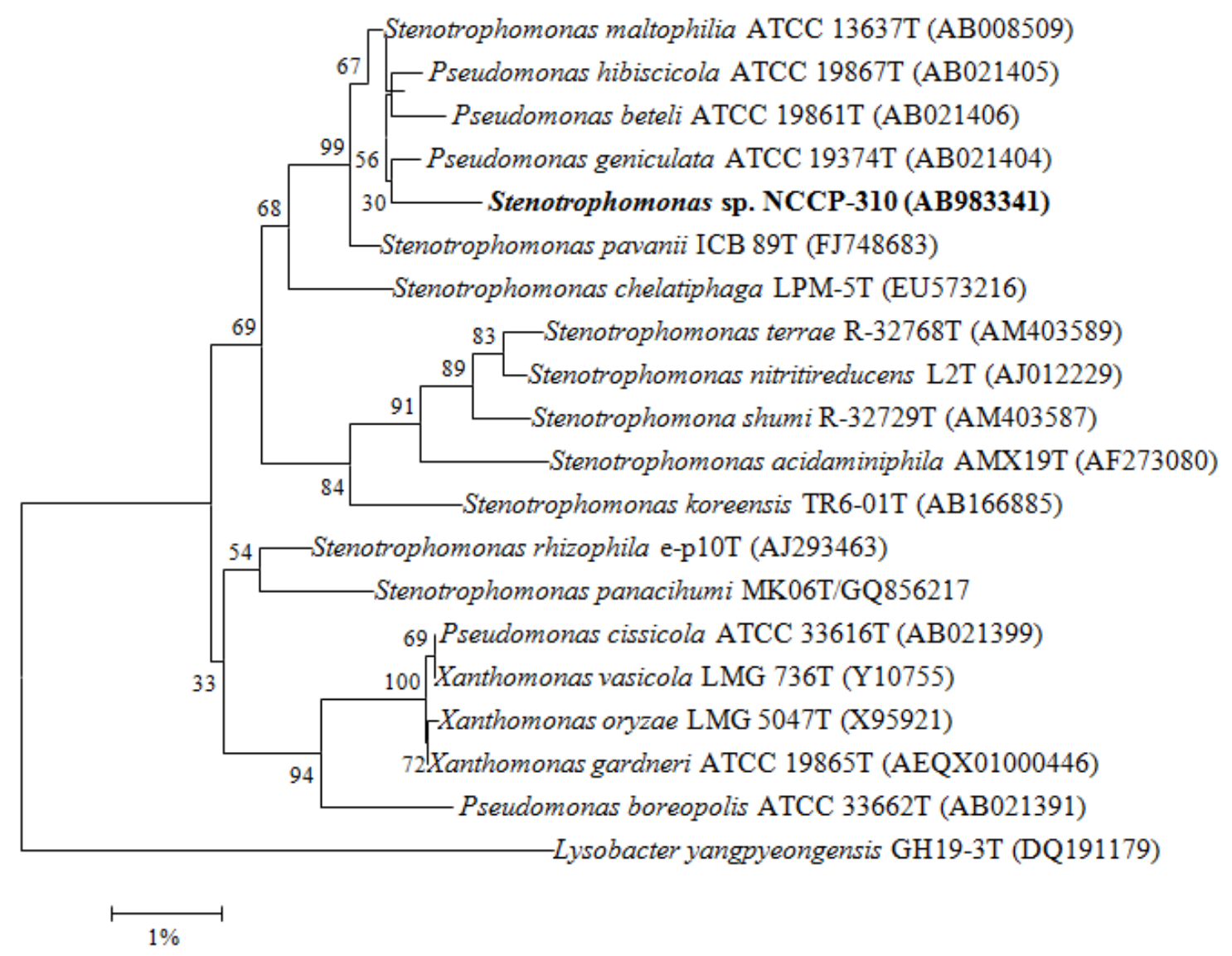

Figure 1. Phylogenetic tree constructed in MEGA-5 with NJ method, showing the interelation of NCCP-310 with other closest matches using Lysobacter yangpyeongensis (DQ191179) as an out group.

Table 1. Biochemical characterization of Stenotrophomonas sp. NCCP-310 and Staphylococcus sp. NCCP-405.

\begin{tabular}{lcc}
\hline Biochemical tests & $\begin{array}{c}\text { Stenotrophomonas sp. } \\
\text { NCCP-310 }\end{array}$ & $\begin{array}{c}\text { Staphylococcus sp. } \\
\text { NCCP-405 }\end{array}$ \\
\hline Arginine dihydrolase & - & - \\
Citrate utilization & + & - \\
Gelatinase & + & - \\
$\mathrm{H}_{2}$ S production & - & - \\
Indole production & - & - \\
Lysine decarboxylase & + & - \\
Ornithine dacarboxylase & - & - \\
Sodium pyruvate & - & - \\
Tryptophane deaminase & - & - \\
Urease & - & + \\
$\beta$-galactosidase & + & + \\
Fermentation/oxidation of: & & - \\
$\quad$ Amygdalin & - & - \\
$\quad$ Arabinose & - & \\
\hline
\end{tabular}




\begin{tabular}{lcc}
\hline Glucose & - & - \\
Inositol & - & - \\
Mannitol & - & - \\
Melibiose & - & - \\
Rhamnose & - & - \\
Sacharose & - & + \\
Sorbitol & - & - \\
$\mathrm{NO}_{2}$ production & + & - \\
Reduction to $_{2}$ gas & - & \\
\hline
\end{tabular}

+ , positive reaction; -, negative reaction. These results are obtained after $48-72 \mathrm{~h}$ of incubation at $28^{\circ} \mathrm{C}$.

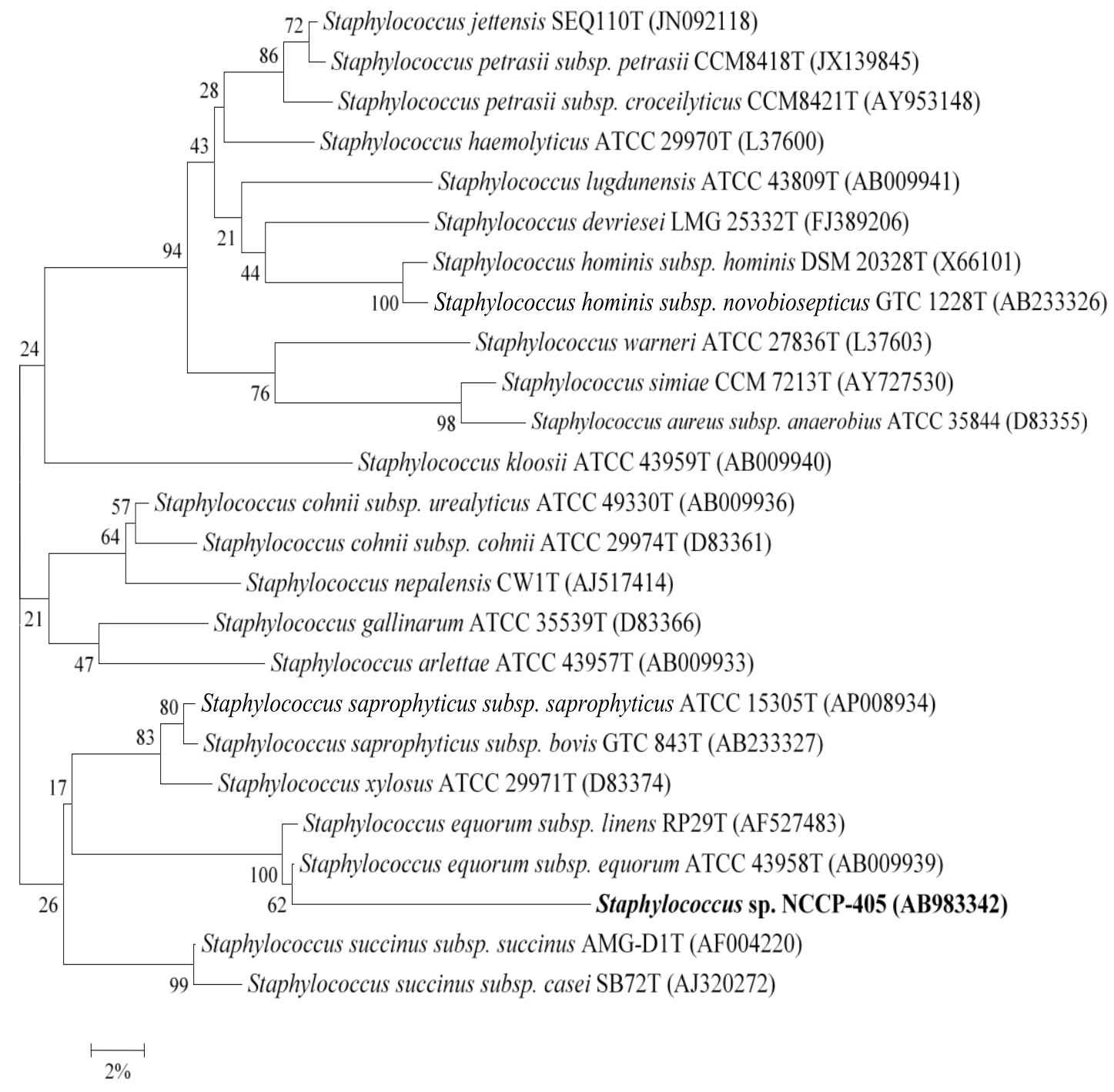

Figure 2. Phylogenetic tree showing the inter-relationships of strain NCCP-405 with the most closely related type species inferred from sequences of $16 \mathrm{~S} r R N A$ gene. The tree was generated using the NJ method. Bootstrap values were expressed as a percentage of 1000 replications.

The bar shows $2 \%$ sequence divergence. 


\section{Phenol tolerance}

Both stains were tested for their growth in MSM broth containing 0, 250, 500, 750 and $1000 \mathrm{mg} \mathrm{L}^{-1}$ phenol. The stain Stenotrophomonas sp. NCCP-310 was incubated for $63 \mathrm{~h}$ and growth was observed at all specified concentrations except $0 \mathrm{mg} \mathrm{L}^{-1}$. Maximum growth was observed at $750 \mathrm{mg} \mathrm{L}^{-1}$ phenol after $53 \mathrm{~h}$ of incubation (Fig. 3a). Similarly, Staphylococcus sp. NCCP-405 was incubated for $86 \mathrm{~h}$ and showed growth at all concentrations except $0 \mathrm{mg} \mathrm{L}^{-1}$. At all the given concentrations, the stain showed a very slow growth up to $12 \mathrm{~h}$. Results indicated the extreme growth of NCCP-405 at $1000 \mathrm{mg} \mathrm{L}^{-1}$ phenol after $72 \mathrm{~h}$ of incubation (Fig. 3 b).

(a)

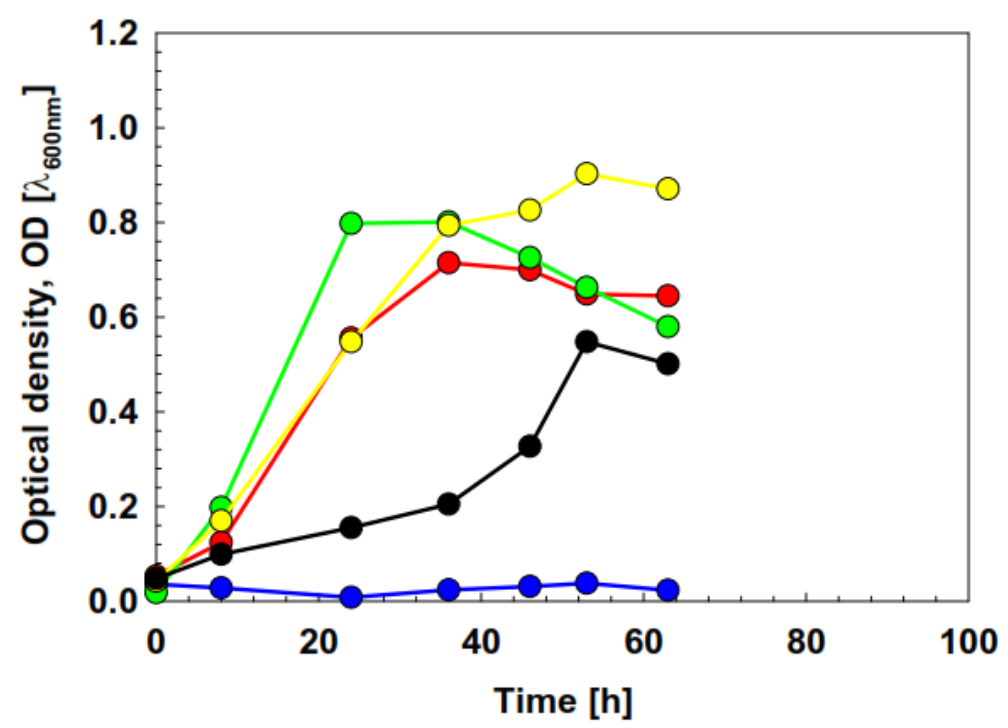

(b)

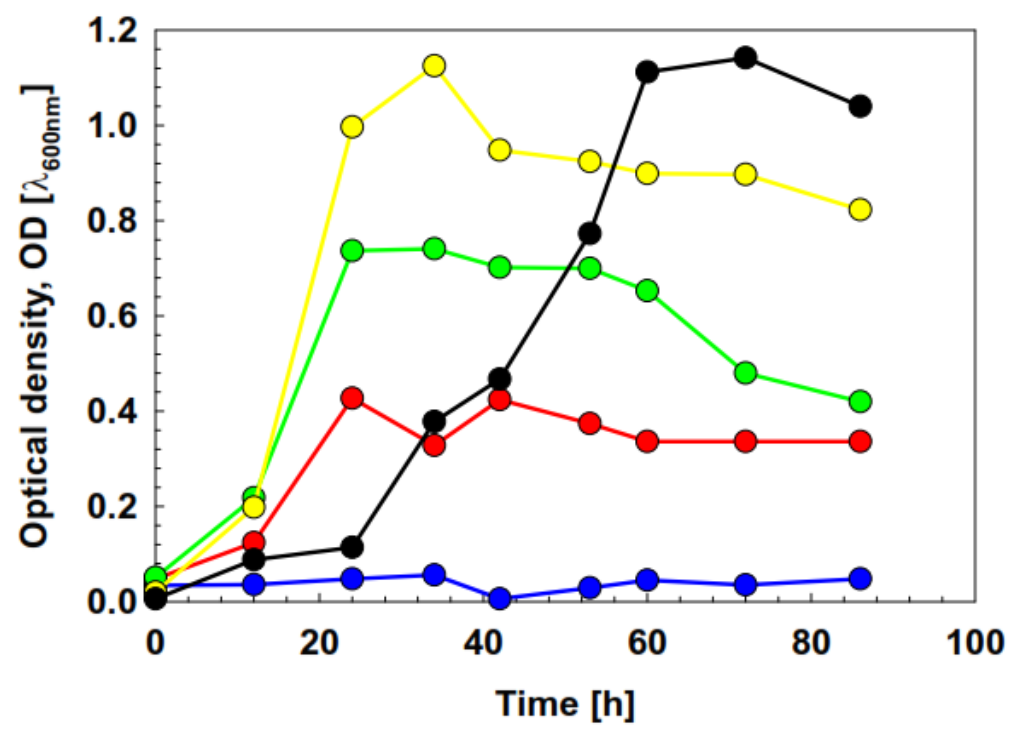

Figure 3. Tolerance of phenol at different concentrations grown at $28^{\circ} \mathrm{C}$ in relation to time scale. (a) Stenotrophomonas sp. NCCP-310 and (b) Staphylococcus sp. NCCP-405. (- $\bullet$ )

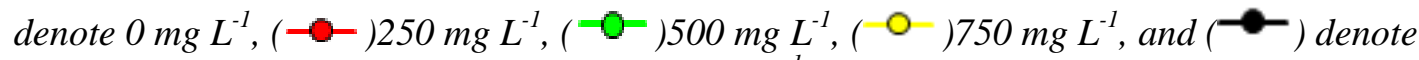
$1000 \mathrm{mg} \mathrm{L}^{-1}$. 
Tolerance of bacteria toward high concentration of phenol may be natural or due to some genetic changes particularly mutation in plasmid carrying gene for phenol degradation (Ajaz et al., 2004) or horizontal gene transfer. Tolerance of bacteria to a particular concentration of phenol is not related to the degradation of such amount. Nagamani et al. (2009) reported the tolerance of Xanthobacter flavus to $1100 \mathrm{mg} \mathrm{L}^{-1}$ of phenol but this strain could not degrade such amount and showed the ability to degrade only $650 \mathrm{mg} \mathrm{L}^{-1}$ phenol. This was because bacteria acquire different mechanism to withstand high concentration of phenol like increase in saturation of lipid membrane like in increase in fatty acid amount (Keweloh et al., 1991) and change in protein expression associated with efflux of phenol from cell (Randall et al., 2007).

\section{Phenol degrading potential and analysis}

Remaining phenol in cultural supernatant was quantified using the equation obtained from the regression analysis of external standards (Fig. $4 a$ and $b$ ). The coefficient of determination $\left(R^{2}\right)$ and adjusted $R^{2}$ values of standards were calculated as 99.09 and $98.9 \%$, respectively. The closeness of both values indicates the accuracy of the model. Two types of controls were used for comparison of phenol degraded by the isolated strains, one control containing $750 \mathrm{mg} \mathrm{L}^{-1}$ phenol in MSM broth (uninoculated) and the other control with no phenol in MSM broth (inoculated). In both controls no growth observed nor observed any degradation of phenol. Similarly, no phenol degradation was detected in control without inoculation.

Stenotrophomonas sp. NCCP-310 was incubated for $74 \mathrm{~h}$ at $28+2^{\circ} \mathrm{C}$ in MSM broth augmented with $750 \mathrm{mg} \mathrm{L}^{-1}$ phenol. The strain degraded such amount in $65 \mathrm{~h}$ with average degradation rate of $15.65 \mathrm{mg} \mathrm{L}^{-1} \mathrm{~h}^{-1}$ for which the approximate doubling time was determined as $11.7 \mathrm{~h}^{-1}$. After $49 \mathrm{~h}$ of incubation the strain showed maximum growth (Fig. 5a) as indicated by OD (0.95). Percentage removal of phenol from MSM by this strain was presented in Fig. $5 b$.

(a)

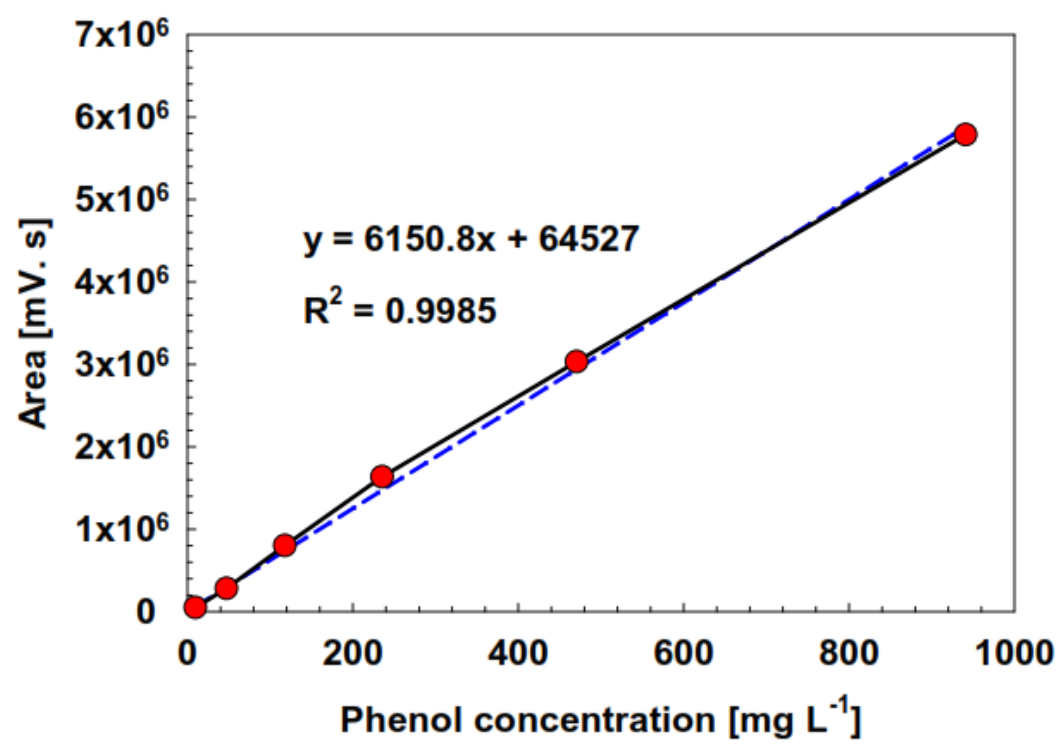


(b)

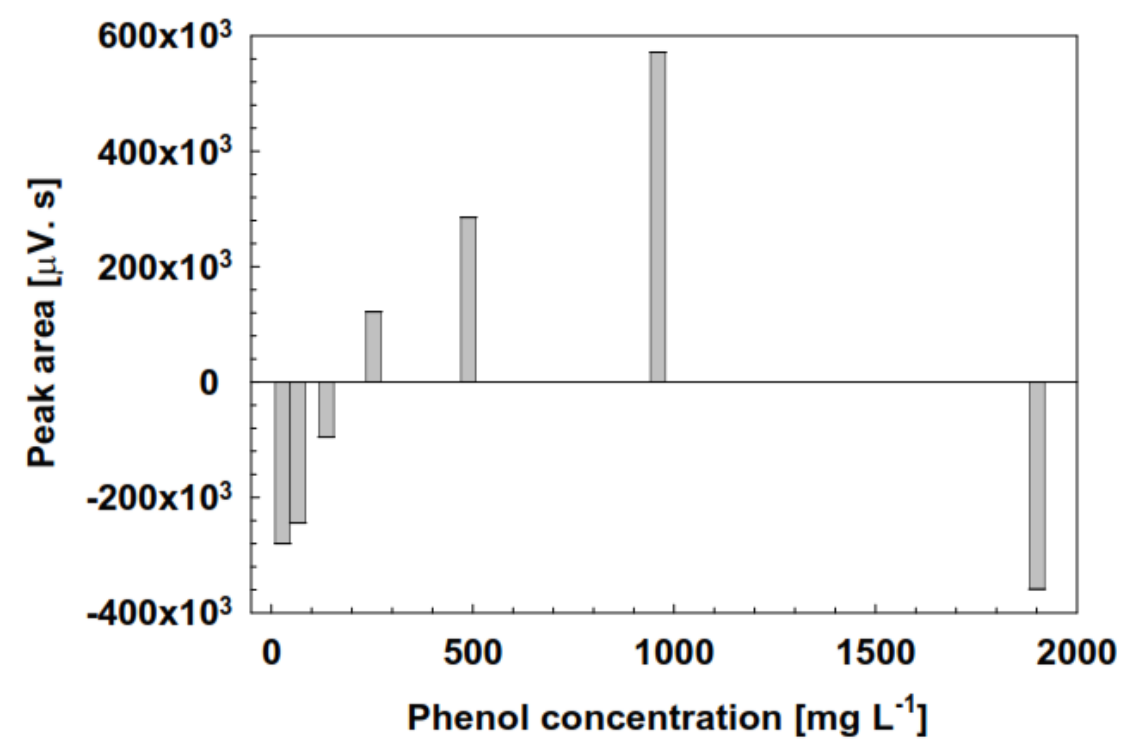

Figure 4. (a) Standard curve and regression analysis presenting peak area and phenol concentration. (b) Residual plot of the external standards used in this study.

The phylogenetic neighbor of Stenotrophomonas sp. NCCP-310 was Stenotrophomonas maltophilia (Palleroni and Bradbury, 1993). This strain was well reported for phenol biodegradation (Gunasundari and Muthukumar, 2013). Phenol degradation pattern of Stenotrophomonas sp. NCCP-310 was found nearly similar to Stenotrophomonas maltophilia K279a (Han et al., 2010) which was able to degrade $805 \mathrm{mg} \mathrm{L}^{-1}$ of phenol and found that this strain degraded such amount in $48 \mathrm{~h}$. Similarly, Urszula et al. (2009) reported the isolation of phenol degrading Stenotrophomonas maltophilia KB2 which degraded $12 \mathrm{mM}$ phenol. Stains of this genus comprises a range of activities including plant growth promoting activity, human pathogenicity, role in nitrogen and sulphur cycles, production of secondary metabolites, metal tolerance and biodegradation of pollutants etc. (Ryan et al., 2009). Degradation of various organic compounds including p-nitrophenol and 4-chlorophenol (Liu et al., 2007), polycyclic aromatic hydrocarbons (Juhasz et al., 2000), benzene, toluene (Lee et al., 2002), EDTA (Kaparullina et al., 2009) validates the natural biodegradation potential of the genus Stenotrophomonas.

Staphylococcus sp. NCCP-405 was incubated for $92 \mathrm{~h}$ at $28 \pm 22^{\circ} \mathrm{C}$ in MSM broth supplemented with $750 \mathrm{mg} \mathrm{L}^{-1}$ of phenol. The strain degraded such amount in $85 \mathrm{~h}$ with the average degradation rate of $11.64 \mathrm{mg} \mathrm{L}^{-1} \mathrm{~h}^{-1}$ for which the approximate doubling time was recorded as $12.95 \mathrm{~h}^{-1}$. After $53 \mathrm{~h}$ of incubation the strain showed maximum growth (Fig. 6a) as indicated by OD (0.924). Percentage removal of phenol from MSM by this strain was presented in Fig. 6b. Among the phylogenetic neighbors of Staphylococcus sp. NCCP-405, no strain is reported for phenol degradation. However, few strains of this genus are documented for bioremediation of phenol. Naresh et al. (2012) reported the isolation of Staphylococcus aureus from effluent which degraded $1000 \mathrm{mg} \mathrm{L}^{-1}$ phenol in 7 days. Prasanna et al. (2008) reported the degradation of $43.94 \%$ of $100 \mathrm{mg} \mathrm{L}^{-1}$ phenol in $120 \mathrm{~h}$. The difference of time to degrade phenol by members of a genus is common and acceptable (Larkin et al., 2005). Similarly, few more strains showed the phenol degrading potential belonging to this genus. Phenol 
degrading pattern of Staphylococcus sp. NCCP-405 is somewhat similar to that of Xanthobacter flavus which was isolated from the soil near dye industry and showed complete degradation of $600 \mathrm{mg} \mathrm{L}^{-1}$ phenol in $120 \mathrm{~h}$. In their work more than $97 \%$ of available phenol was degraded after $80 \mathrm{~h}$ of incubation but after that the process was prolonged (Nagamani et al., 2009). Comparatively, Stenotrophomonas sp. NCCP-310 degraded $750 \mathrm{mg} \mathrm{L}^{-1}$ phenol faster than Staphylococcus sp. NCCP-405. The presence of phenol degradation potential of phylogenetically diverse bacteria indicates the wide distribution of this trait. However, toxicity of phenol at high concentration showed growth with phenol by the strain Staphylococcus sp. NCCP-405 whose closely related strains don't have phenol degradation capacity indicates that horizontal gene transfer might have an important role in widely distribution of this trait.

(a)

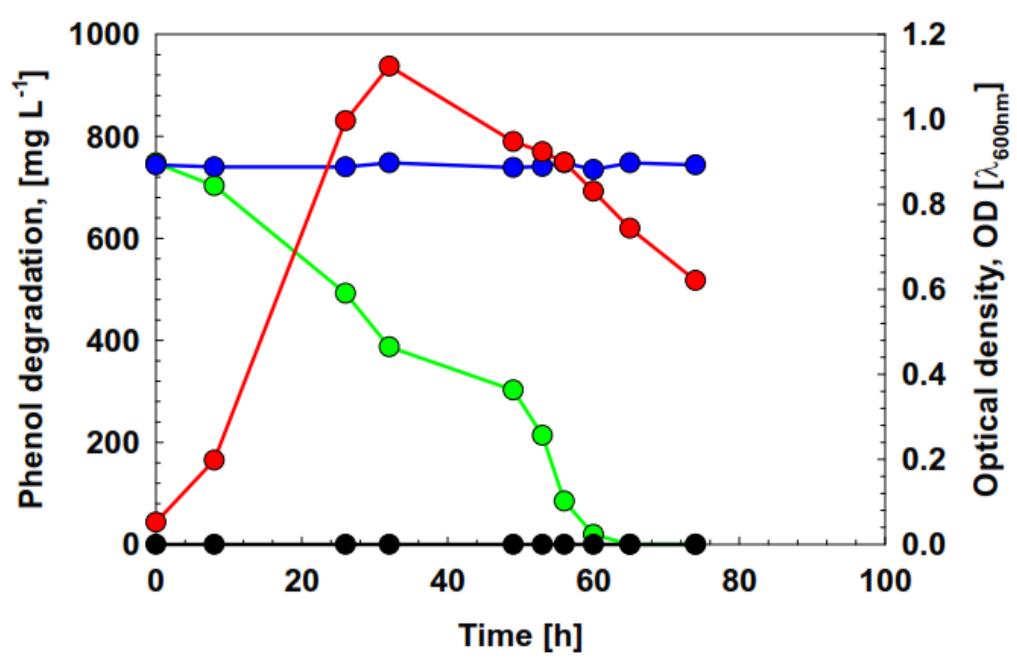

(b)

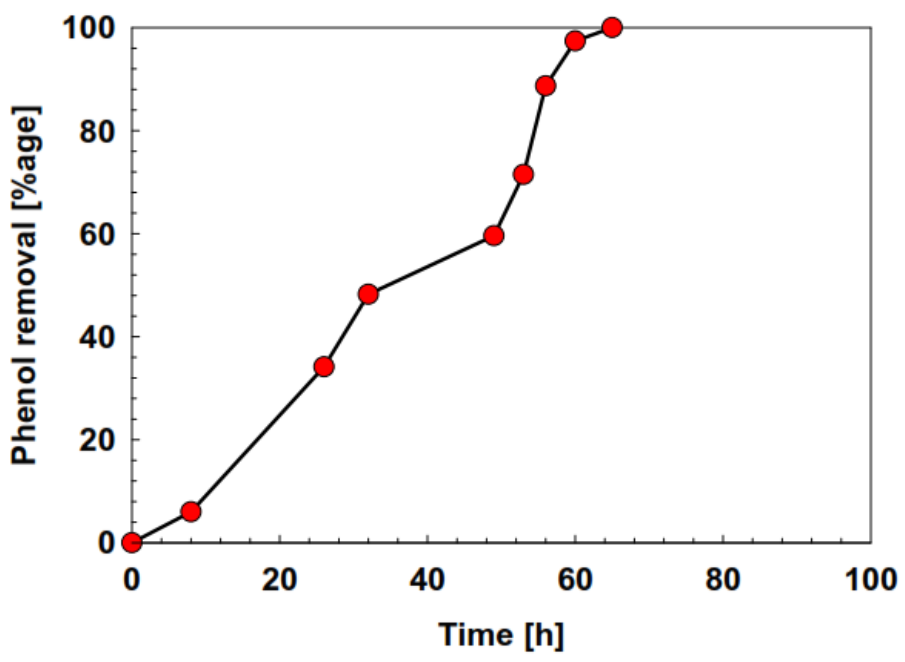

Figure 5. (a) Degradation of phenol $\left(750 \mathrm{mg} \mathrm{L}^{-1}\right)$ and growth as measured by optical density at $600 \mathrm{~nm}$ of NCCP-310. ( $\bullet-)$ denote phenol concentration in control (without inoculum), $\left.(-)^{-}\right)$denote phenol concentration in inoculum, $(-\rightarrow)$ present observed OD in inoculum and (-) present OD in control. (b) Percentage phenol removal from MSM broth by NCCP-310. 
(a)

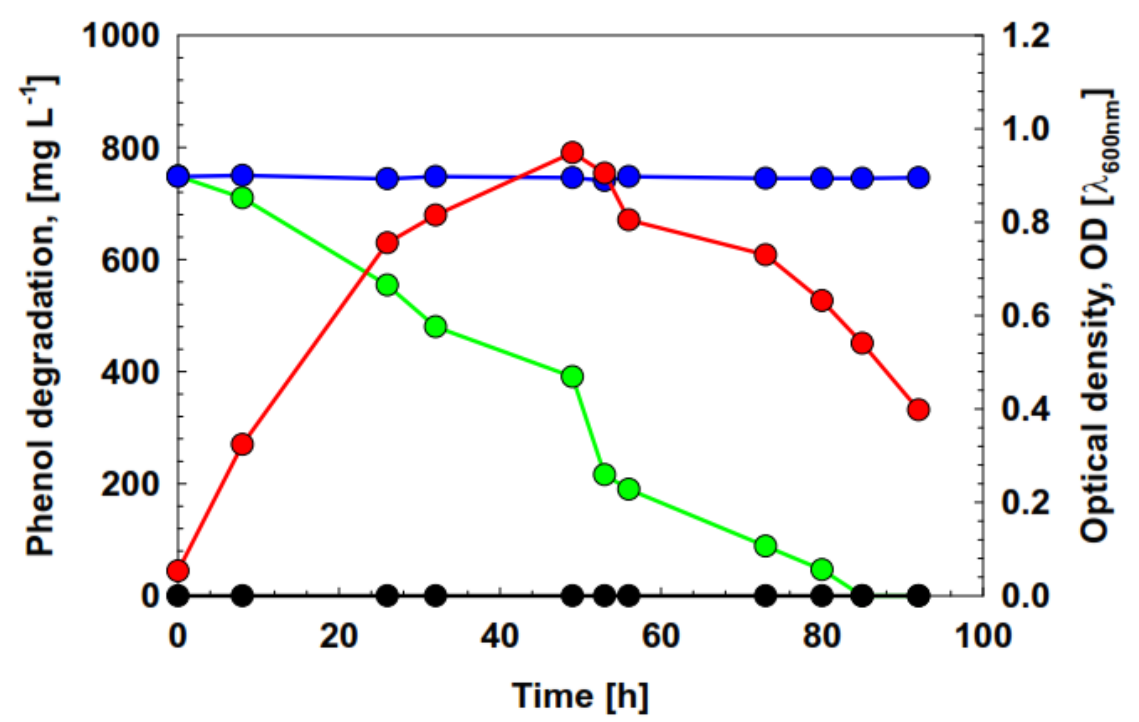

(b)

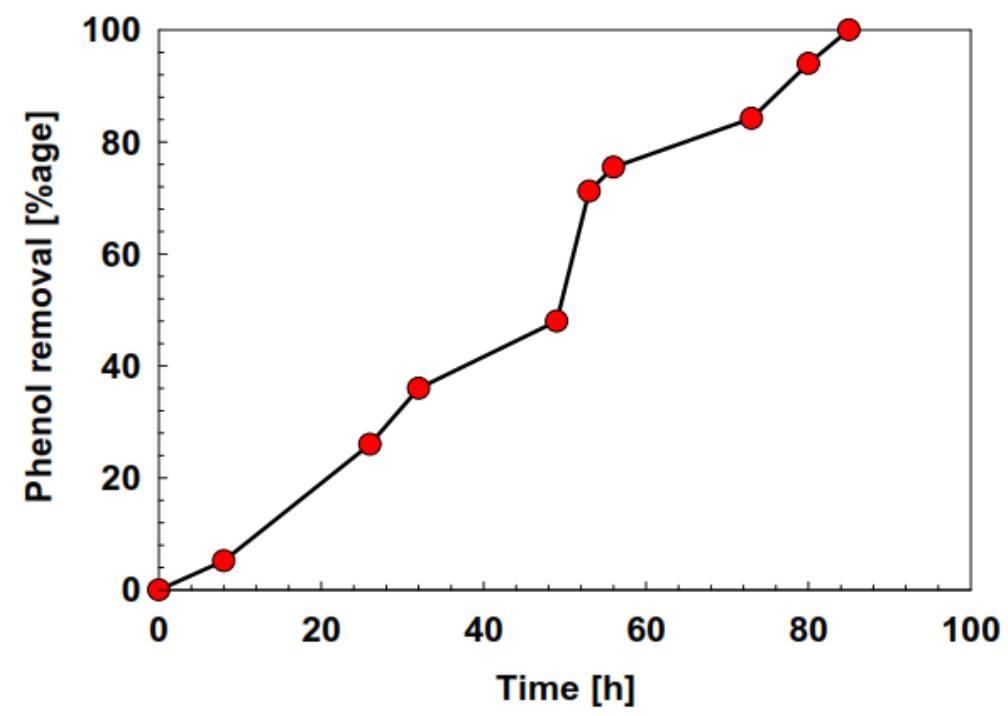

Figure 6. (a) Degradation of phenol $\left(750 \mathrm{mg} \mathrm{L}^{-1}\right)$ and growth as measured by optical density at $600 \mathrm{~nm}$ of NCCP-405. ( $\bullet-)$ denote phenol concentration in control (without inoculum), $(-\circ)$ denote phenol concentration in inoculum, $(-\bullet)$ present observed OD in inoculum and $(-$ ) present $O D$ in control. (b) Percentage phenol removal from MSM broth by NCCP-405.

\section{Conclusion}

Present study delivers a useful guideline for identification of bacteria based on sequence analysis of 16S rRNA gene. In this study two bacteria strains NCCP-310 and NCCP-405 were isolated through enrichment process from two different contaminated sites. These strains showed growth up to $1000 \mathrm{mg} \mathrm{L}^{-1}$ of phenol. The isolated strains were found to degrade $750 \mathrm{mg} \mathrm{L}^{-1}$ phenol, given as sole source of carbon and energy. These degrade phenol in 65 and 85 h respectively. 
Acknowledgements. This work was supported by financial assistance from PSDP funded Project Research for Agricultural Development Project under a sub-project (Grant No. CS-55/RADP/PARC to Iftikhar Ahmed) entitled "Establishment of Microbial Bio-Resource Laboratories: National Culture Collection of Pakistan (NCCP)" from Pakistan Agricultural Research Council, Islamabad, Pakistan.

\section{REFERENCES}

[1] Ahmad, N., Ahmed, I., Shahzad, A., Khalid, N., Mehboob, F., Ahad, K. Ali, G. M. (2014): Molecular identification and characterization of Pseudomonas sp. NCCP-407 for phenol degradation isolated from industrial waste. - Journal of the Korean Society for Applied Biological Chemistry 57: 341-346.

[2] Ahmed, I., Yokota, A., Fujiwara, T. (2007): A novel highly boron tolerant bacterium, Bacillus boroniphilus sp. nov., isolated from soil, that requires boron for its growth. Extremophiles 11, 217-224.

[3] Ahmed, W., Ahmed, A., Ahmad, A., Randhawa, M. A., Ahmad, R. Khalid, N. (2012): Heavy Metal Contamination in Vegetables Grown in Rawalpindi, Pakistan. - Journal of the Chemical Society of Pakistan 34: 914-919.

[4] Ajaz, M., Noor, N., Rasool, S. A. Khan, S. A. (2004): Phenol resistant bacteria from soil: identification-characterization and genetical studies. - Pakistan Journal of Botany 36: 415-424.

[5] Anzai, Y., Kim, H., Park, J.Y., Wakabayashi, H. Oyaizu, H. (2000): Phylogenetic affiliation of the pseudomonads based on 16S rRNA sequence. -International Journal of Systematic and Evolutionary Microbiology 50: 1563-1589.

[6] Arutchelvan, V., Kanakasabai, V., Elangovan, R., Nagarajan, S. Muralikrishnan, V. (2006): Kinetics of high strength phenol degradation using Bacillus brevis. -Journal of Hazardous Materials 129: 216-222.

[7] Carbajo, J. B., Boltes, K. Leton, P. (2010): Treatment of phenol in an anaerobic fluidized bed reactor (AFBR): continuous and batch regime. -Biodegradation 21: 603-613.

[8] Dunbar, J., White, S. Forney, L. (1997): Genetic diversity through the looking glass: effect of enrichment bias. -Applied and Environmental Microbiology 63: 1326-1331.

[9] Fialova, A., Boschke, E. Bley, T. (2004): Rapid monitoring of the biodegradation of phenol-like compounds by the yeast Candida maltosa using BOD measurements. International biodeterioration \& biodegradation 54: 69-76.

[10] Giti, E., Mehdi, H. Nasser, G. (2005): Development of a microtitre plate method for determination of phenol utilization, biofilm formation and respiratory activity by environmental bacterial isolates.-International Journal of biodegradation and biodeterioration 56: 231-235.

[11] Godjevargova, T., Ivanova, D., Alexieva, Z. Dimova, N. (2003): Biodegradation of toxic organic components from industrial phenol production waste waters by free and immobilized Trichosporon cutaneum R57. - Process Biochemistry 38: 915-920.

[12] Gunasundari, D. Muthukumar, K. (2013): Simultaneous Cr (VI) reduction and phenol degradation using Stenotrophomonas sp. isolated from tannery effluent contaminated soil. -Environmental Science and Pollution Research 20: 6563-6573.

[13] Han, H.J., Fang, F., Ma, W.C., Xun, C.Y., Wang, W., Li, H.Q. (2010): Phenoloxidase activity of phenol-degrading bacteria. -Bioinformatics and Biomedical Technology, International Conference, IEEE, pp. 23-26.

[14] Hugh, R. (1981): Note: Pseudomonas maltophilia sp. nov., nom. rev. - International Journal of Systematic Bacteriology 31: 195-195.

[15] Idris, A. Saed, K. (2002): Degradation of phenol in wastewater using anolyte produced from electrochemical generation of brine solution. - Global Nest 4: 139-44.

[16] Juhasz, A. L., Stanley, G. A. Britz, M. L. (2000): Microbial degradation and detoxification of high molecular weight polycyclic aromatic hydrocarbons by 
Stenotrophomonas maltophilia strain VUN 10,003. - Letters in Applied Microbiology 30: 396-401.

[17] Kaparullina, E., Doronina, N., Chistyakova, T. Trotsenko, Y. (2009): Stenotrophomonas chelatiphaga sp. nov., a new aerobic EDTA-degrading bacterium. -Systematic and Applied Microbiology 32: 157-162.

[18] Keweloh, H., Diefenbach, R. Rehm, H.J. (1991): Increase of phenol tolerance of Escherichia coli by alterations of the fatty acid composition of the membrane lipids. Archives of Microbiology 157: 49-53.

[19] Kwon, K. H. Yeom, S. H. (2009): Optimal microbial adaptation routes for the rapid degradation of high concentration of phenol. -Bioprocess and Biosystems Engineering 32: 435-442.

[20] Larkin, M. J., Kulakov, L. A. Allen, C. C. (2005): Biodegradation and Rhodococcusmasters of catabolic versatility. -Current Opinion in Biotechnology 16: 282-290.

[21] Lee, E. Y., Jun, Y. S., Cho, K.-S. \& Ryu, H. W. (2002): Degradation characteristics of toluene, benzene, ethylbenzene, and xylene by Stenotrophomonas maltophilia T3-c. Journal of the Air \& Waste Management Association 52: 400-406.

[22] Liu, Z., Yang, C. \& Qiao, C. (2007). Biodegradation of p-nitrophenol and 4-chlorophenol by Stenotrophomonas sp. -FEMS Microbiology Letters 277: 150-156.

[23] Nagamani, A., Soligalla, R. Lowry, M. (2009): Isolation and characterization of phenol degrading Xanthobacter flavus. -African Journal of Biotechnology 8: 5449-5453.

[24] Naresh, B., Honey, P. Vaishali, S. (2012): Biodegradation of phenol by a bacterial strain isolated from a phenol contaminated site in India. -Research Journal of Environment Sciences 1: 46-49.

[25] Palleroni, N. J. Bradbury, J. F. (1993): Stenotrophomonas, a new bacterial genus for Xanthomonas maltophilia (Hugh 1980) Swings et al. 1983. -International Journal of Systematic Bacteriology 43: 606-609.

[26] Prasanna, N., Saravanan, N., Geetha, P., Shanmugaprakash, M., Rajasekaran, P. (2008): Biodegradation of Phenol and Toluene by Bacillus sp., Pseudomonas sp., and Staphylococcus sp. Isolated from Pharmaceutical Industrial Effluent. 7: 20-24.

[27] Quan, X., Shi, H., Zhang, Y., Wang, J. Qian, Y. (2004). Biodegradation of 2, 4dichlorophenol and phenol in an airlift inner-loop bioreactor immobilized with Achromobacter sp. -Separation and Purification Technology 34: 97-103.

[28] Randall, L., Cooles, S., Coldham, N., Penuela, E., Mott, A., Woodward, M., Piddock, L. Webber, M. (2007): Commonly used farm disinfectants can select for mutant Salmonella enterica serovar Typhimurium with decreased susceptibility to biocides and antibiotics without compromising virulence. -Journal of Antimicrobial Chemotherapy 60: 12731280.

[29] Rocha, L. L., de Aguiar Cordeiro, R., Cavalcante, R. M., do Nascimento, R. F., Martins, S. C. S., Santaella, S. T. Melo, V. M. M. (2007): Isolation and characterization of phenoldegrading yeasts from an oil refinery wastewater in Brazil. -Mycopathologia 164: 183188.

[30] Roohi, A., Ahmed, I., Iqbal, M. Jamil, M. (2012): Preliminary isolation and characterization of halotolerant and halophilic bacteria from salt mines of Karak, Pakistan. -Pakistan Jounal of Botany 44: 365-370.

[31] Ryan, R. P., Monchy, S., Cardinale, M., Taghavi, S., Crossman, L., Avison, M. B., Berg, G., van der Lelie, D. Dow, J. M. (2009): The versatility and adaptation of bacteria from the genus Stenotrophomonas. -Nature Reviews Microbiology 7: 514-525.

[32] Saravanan, P., Pakshirajan, K. Saha, P. (2008): Kinetics of phenol and m-cresol biodegradation by an indigenous mixed microbial culture isolated from a sewage treatment plant. -Journal of Environmental Sciences 20: 1508-1513.

[33] Tamura, K., Peterson, D., Peterson, N., Stecher, G., Nei, M. Kumar, S. (2011): MEGA5: molecular evolutionary genetics analysis using maximum likelihood, evolutionary 
distance, and maximum parsimony methods. -Molecular Biology and Evolution 28: 2731-2739.

[34] Thompson, J. D., Higgins, D. G. Gibson, T. J. (1994): CLUSTAL W: improving the sensitivity of progressive multiple sequence alignment through sequence weighting, position-specific gap penalties and weight matrix choice. -Nucleic acids research 22: 4673-4680.

[35] Urszula, G., Izabela, G., Danuta, W. Sylwia, Ł. (2009): Isolation and characterization of a novel strain of Stenotrophomonas maltophilia possessing various dioxygenases for monocyclic hydrocarbon degradation. -Brazilian Journal of Microbiology 40: 285-291.

[36] US EPA (2007): National Recommended Water Quality Criteria. Washington, USA: U.S. Environmental Protection Agency Office of Water

[37] Zhu, X., Tian, J. Chen, L. (2012) : Phenol degradation by isolated bacterial strains: kinetics study and application in coking wastewater treatment. -Journal of Chemical Technology and Biotechnology 87: 123-129. 